Supporting Information to

\title{
Improving Structural and Moisture Stability of P2-Layered Cathode
}

\section{Materials for Sodium-Ion Batteries}

Jinsen Jiang, ${ }^{1+}$ Hung-Chieh He, ${ }^{2+}$ Chen Cheng, ${ }^{1}$ Tianran Yan, ${ }^{1}$ Xiao Xia, ${ }^{1}$ Manling Ding, ${ }^{1}$ Le He, ${ }^{1}$ Ting-Shan Chan, ${ }^{2, *}$ Liang Zhang ${ }^{1, *}$

1. Institute of Functional Nano \& Soft Materials (FUNSOM), Jiangsu Key Laboratory for Carbon-Based Functional Materials \& Devices, Soochow University, 199 Ren'ai Road, Suzhou 215123, China

2. National Synchrotron Radiation Research Center, Hsinchu 30076, Taiwan

Email: liangzhang2019@suda.edu.cn (L.Z.); chan.ts@ @srrc.org.tw (T.S.C) 


\section{Experimental method}

\section{Material Synthesis}

The $\mathrm{Na}_{0.6} \mathrm{Ni}_{0.3-\mathrm{x}} \mathrm{Mn}_{0.7} \mathrm{Cu}_{\mathrm{x}} \mathrm{O}_{2}$ samples $(\mathrm{x}=0,0.05,0.1,0.2)$ were obtained traditional solid-state reaction. A desired stoichiometric amounts of $\mathrm{Na}_{2} \mathrm{CO}_{3}$ (Aladdin, 5\% excess to compensate for the loss of sodium during calcining), $\mathrm{MnCO}_{3}$ (Aladdin), $\mathrm{Ni}(\mathrm{OH})_{2}$ (Alfa) and $\mathrm{CuO}$ (Aladdin) precursors were mixed by ball milling for $12 \mathrm{~h}$. Firstly, the dry powder is ground by hand with a mortar and pestle and then preheated at $500{ }^{\circ} \mathrm{C}$ for 5 hours to remove the remaining carbonate. The dried powders were hand-ground using mortar and pestle and then pressed into $13 \mathrm{~mm}$ pellets using a press die. Finally, the pellets were calcined in air at $900{ }^{\circ} \mathrm{C}$ for 15 hours, cooled naturally to room temperature to obtain final powders, and then quickly transferred to a glove box filled with argon gas for preservation.

\section{Material characterization}

The crystalline structures of the final products were investigated with lab X-ray diffraction (XRD, Empyrean, Malvern Panalytical, Almelo, Netherlands) using $\mathrm{Cu} \mathrm{K} \alpha$ as the X-ray source between $2 \theta=10$ and $80^{\circ}$. Rietveld refinement was conducted by the program of GSAS. The morphology of the samples was characterized by scanning electron microscopy (SEM, G500, Zeiss, Oberkochen, Germany). The high resolution lattice fringes and EDS distribution of the samples were observed by transmission electron microscopy (TEM, 200X, Talos, Thermo Fisher Scientific, Waltham, MA, USA). X-ray photoelectron spectroscopy (XPS) was conducted on a ULTRA DLD X-ray photoelectron spectrometer.

\section{Electrochemical Measurements}

Electrochemistry of cathode materials was measured using sodium metal-pair electrodes in 
2032coin cells. Active material was mixed with acetylene black and polyvinylidene fluoride (PVDF) (8:1:1) was dispersed in N-methyl-2-pyrrolidone (NMP) to prepare cathode electrode. Then the uniform slurry was cast on the carbon-coated aluminum foil and dried in vacuum at $120{ }^{\circ} \mathrm{C}$ for $12 \mathrm{~h}$. The electrodes were punched and pressed with a diameter of $13 \mathrm{~mm}$ and a mass loading of $3.5 \mathrm{mg} \mathrm{cm}^{-2}$ (corresponding to $2.8 \mathrm{mg} \mathrm{cm}^{-2}$ of active material). The coin cells were assembled in a glove box in an argon atmosphere. Then the metal sodium foil was used as the negative electrode and the glass fiber filter was used as the separator. 1.0 $\mathrm{M} \mathrm{NaPF}_{6}$ was added to the polycarbonate (PC) and ethylene fluoride carbonate (FEC, 5\% by volume) was used as the electrolyte. On the Land BT2000 battery test system, a charge and discharge test at room temperature was performed in the voltage range of 2.0-4.5 V. In the GITT experiment, the cells were charged at $0.05 \mathrm{C}$ for 30 minutes and then relaxed for 1 hour. The simplified formula for calculating the diffusion coefficient of sodium ions is as follows:

$\mathrm{D}=4 / \pi \tau\left(\mathrm{m}_{\mathrm{B}} \mathrm{V}_{\mathrm{m}} / \mathrm{M}_{\mathrm{B}} \mathrm{S}\right)^{2}\left(\nabla \mathrm{E}_{\tau} / \nabla \mathrm{E}_{\mathrm{s}}\right)^{2}$

Where $\mathrm{D}$ is the sodium ion diffusion coefficient, and $\nabla \mathrm{E}_{\tau}$ and $\nabla \mathrm{E}_{\mathrm{s}}$ represent the total voltage change and steady-state voltage change during a titration process, respectively. $\mathrm{m}_{\mathrm{B}}$ is the mass of the active material in the electrode, and $\mathrm{M}_{\mathrm{B}}$ is the molecular weight of the active material in the electrode. $\mathrm{v}_{\mathrm{m}}$ is the molar volume. $\mathrm{S}$ is the surface area of the cathode. $\tau$ is the time to apply a constant current during a single titration. ${ }^{1,2}$

\section{XAS experiments}

XAS data were collected from the SSRF (beamline 02B02 and 11B), BSRF (beamline 1W1B), and TLS (beamline 16A, 20A, 01C). Ni K-edge spectra were collected from beamline 11B of SSRF. Cu K-edge spectra were collected from beamline 1W1B of BSRF. Mn K-edge spectra were 
collected from beamline 16A and 01C of TLS. Ni and Cu L-edge spectra were collected from beamline 02B02 of SSRF. Mn L-edge spectra were collected from beamline 20A of TLS. All samples were disassembled immediately after being cycled to a specific voltage, and immediately rinsed with anhydrous dimethyl carbonate (DMC) several times to wash away the remaining electrolyte on the surface. For Mn L-edge sXAS data, the reference spectra of $\mathrm{MnO}\left(\mathrm{Mn}^{2+}\right)$, $\mathrm{Mn}_{2} \mathrm{O}_{3}\left(\mathrm{Mn}^{3+}\right)$ and $\mathrm{MnO}_{2}\left(\mathrm{Mn}^{4+}\right)$ display dramatically different absorption profiles. Previous studies have demonstrated that Mn compounds for which Mn occupies octahedral positions exhibit similar Mn L-edge absorption spectra for the same Mn valence state in different ligands and crystal structure systems. This allows us to quantitatively analyze the evolution of the concentration of $\mathrm{Mn}^{4+}, \mathrm{Mn}^{3+}$, and $\mathrm{Mn}^{2+}$ through simple simulations based on linear combination of the reference spectra. ${ }^{3,4}$
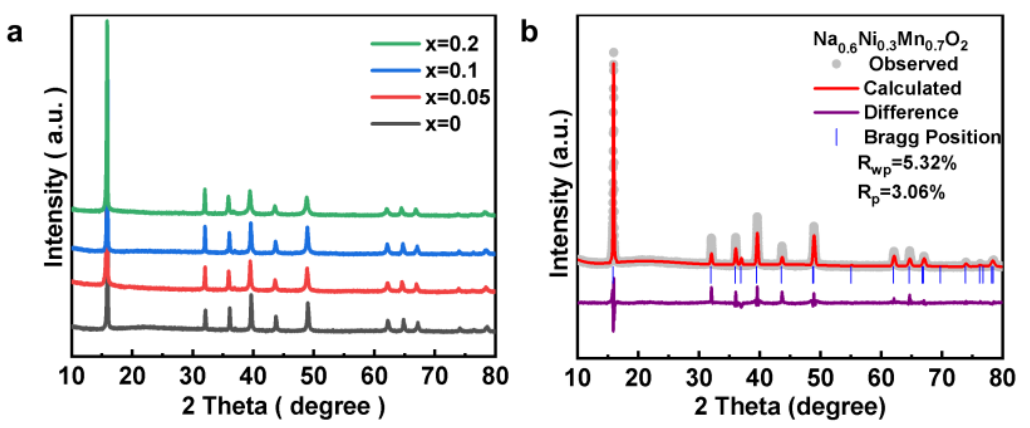

Figure S1. (a)XRD patterns of the as-synthesized $\mathrm{Na}_{0.6} \mathrm{Ni}_{0.3-\mathrm{x}} \mathrm{Mn}_{0.7} \mathrm{Cu}_{\mathrm{x}} \mathrm{O}_{2}$ samples $(\mathrm{x}=$ 0, 0.05, 0.1, 0.2). (b) Rietveld refinement of XRD data for P2-type NNMO.
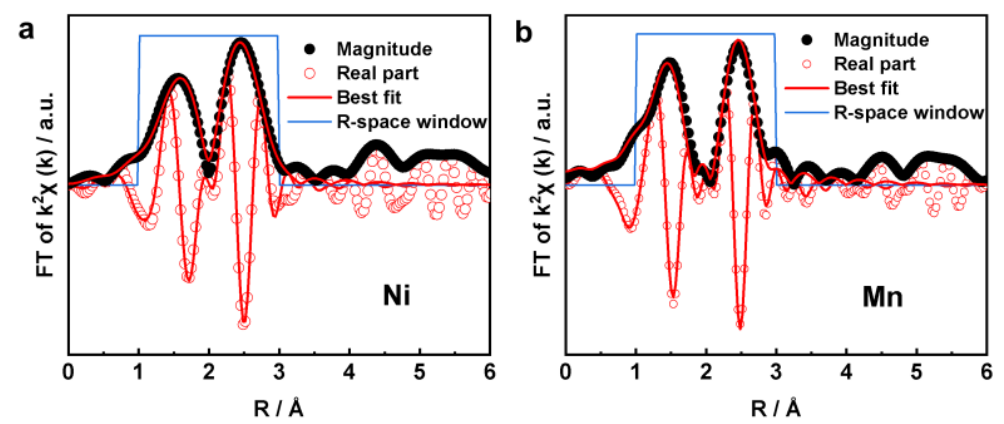

Figure S2. The least-square fits of the calculated FT-EXAFS phase and amplitude functions to the 
experimental EXAFS spectra for (a) Ni and (b) Mn K-edge spectra of NNMO.

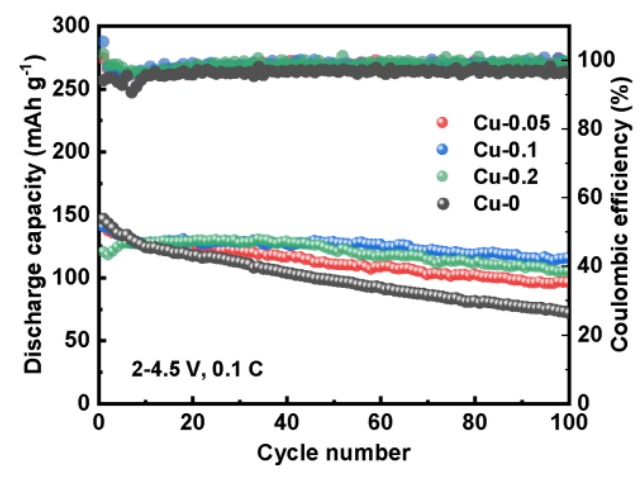

Figure S3. The cycling performances of the as-prepared $\mathrm{Na}_{0.6} \mathrm{Ni}_{0.3-\mathrm{x}} \mathrm{Mn}_{0.7} \mathrm{Cu}_{\mathrm{x}} \mathrm{O}_{2}$ samples $(\mathrm{x}=0$,

$0.05,0.1,0.2)$ electrodes at $0.1 \mathrm{C}$ in the voltage range of $2-4.5 \mathrm{~V}$.

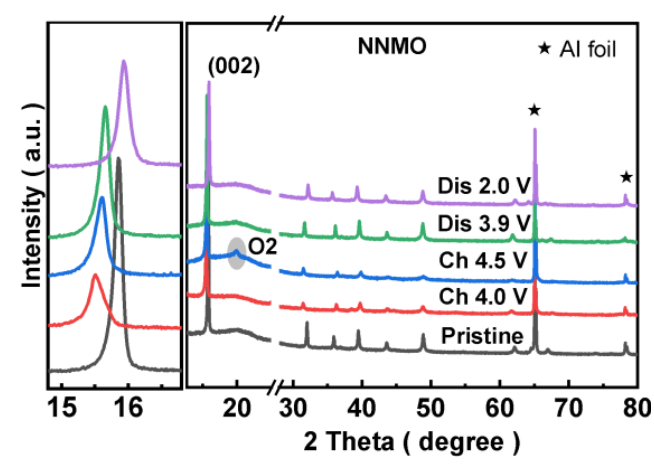

Figure S4. Ex-situ XRD pattern of NNMO during the first charge/discharge cycle at $0.1 \mathrm{C}$ in the voltage range of $2-4.5 \mathrm{~V}$.

a
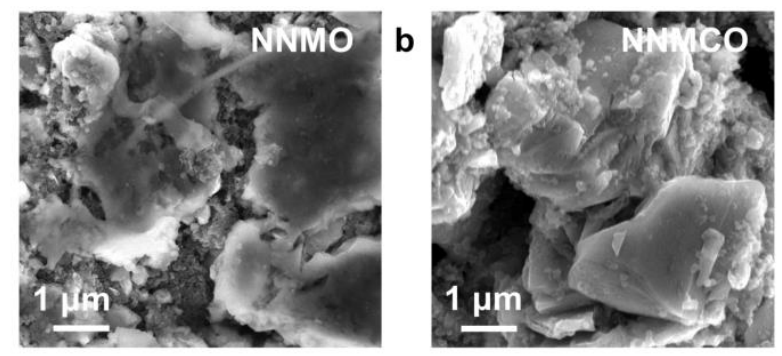

Figure S5. SEM results of (a) NNMO and (b) NNMCO electrodes after 100 cycles.
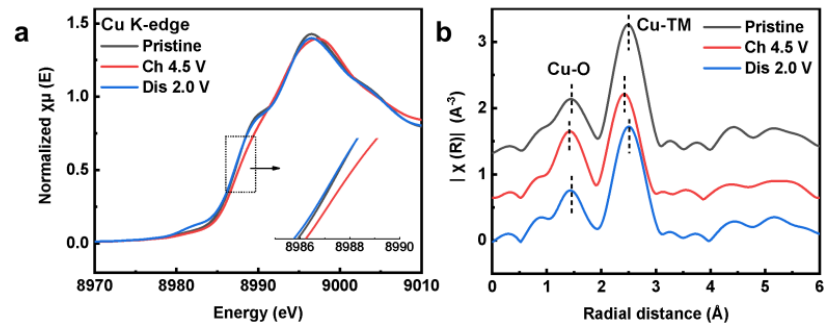

Figure S6. Cu K-edge (a) XANES and (b) EXAFS spectra of NNMCO electrodes in the first 
cycle.
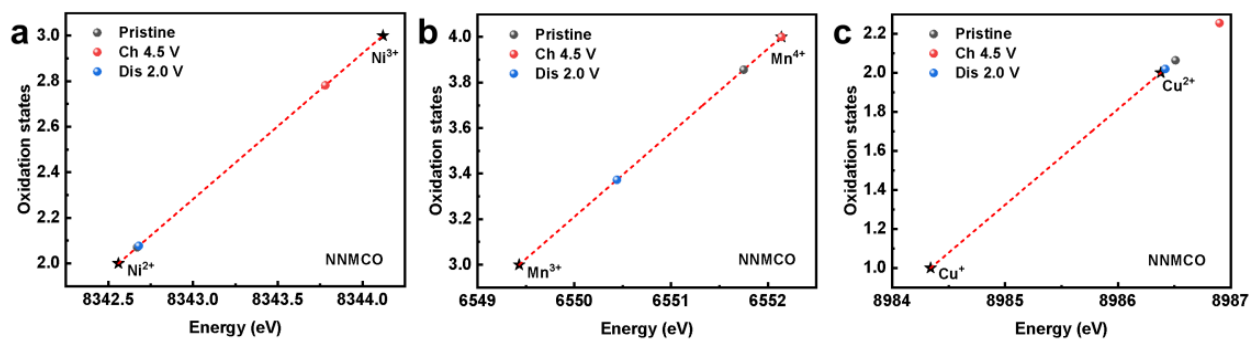

Figure S7. Fitted linear relationship between the absorption edge at half height of the corresponding TM K-edge XANES spectrum and oxidation state of $\mathrm{Ni}, \mathrm{Mn}$, and $\mathrm{Cu}$ of NNMCO at different states of charge for the first cycle in the voltage range of 2.0-4.5 V.
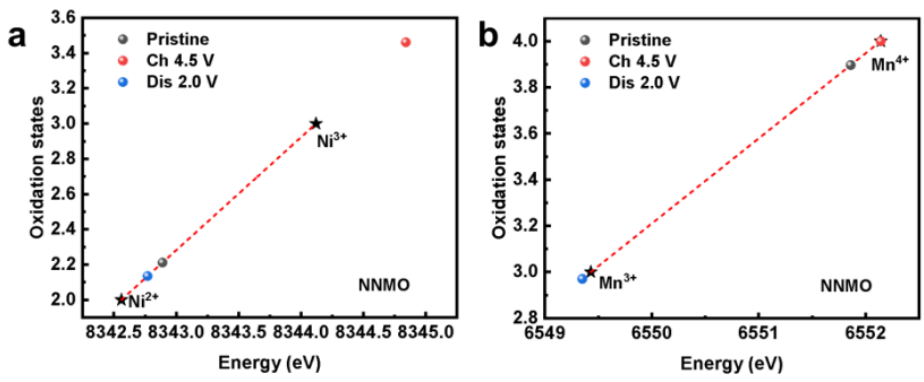

Figure S8. Fitted linear relationship between the absorption edge at half height of the corresponding Ni and Mn K-edge XANES spectra and oxidation state of NNMO at different states of charge for the first cycle in the voltage range of 2.0-4.5 V.

a

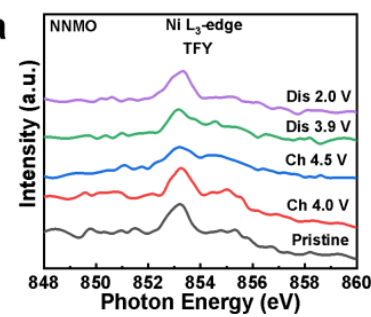

C

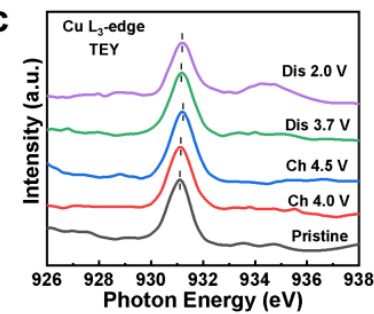

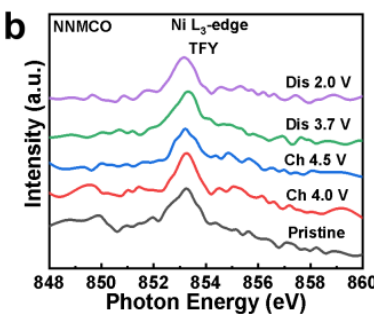

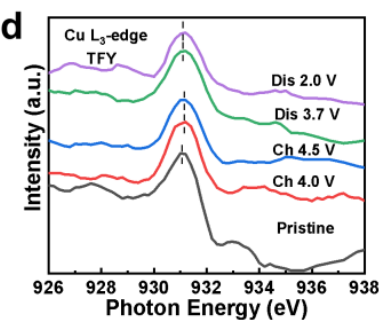

Figure S9. (a, b) Ni $\mathrm{L}_{3}$-edge TFY spectra of NNMO and NNMCO, respectively. (c, d) $\mathrm{Cu} \mathrm{L}_{3}$-edge TEY and TFY spectra of NNMCO, respectively. 
a

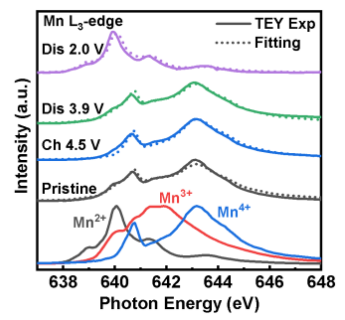

C

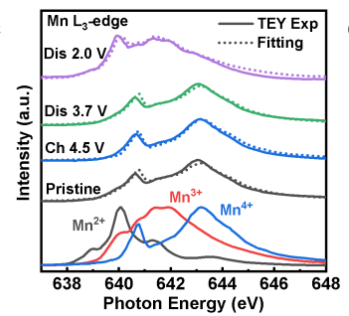

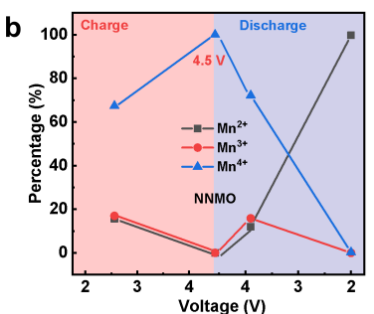

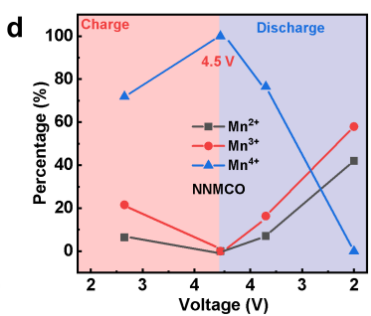

Figure S10. (a, c) Mn L $\mathrm{L}_{3}$-edge experimental (solid line) and fitted (dotted line) TEY spectra of NNMO and NNMCO, respectively. (b, d) The valence distribution of Mn on the surface as a function of voltage for NNMO and NNMCO, respectively.
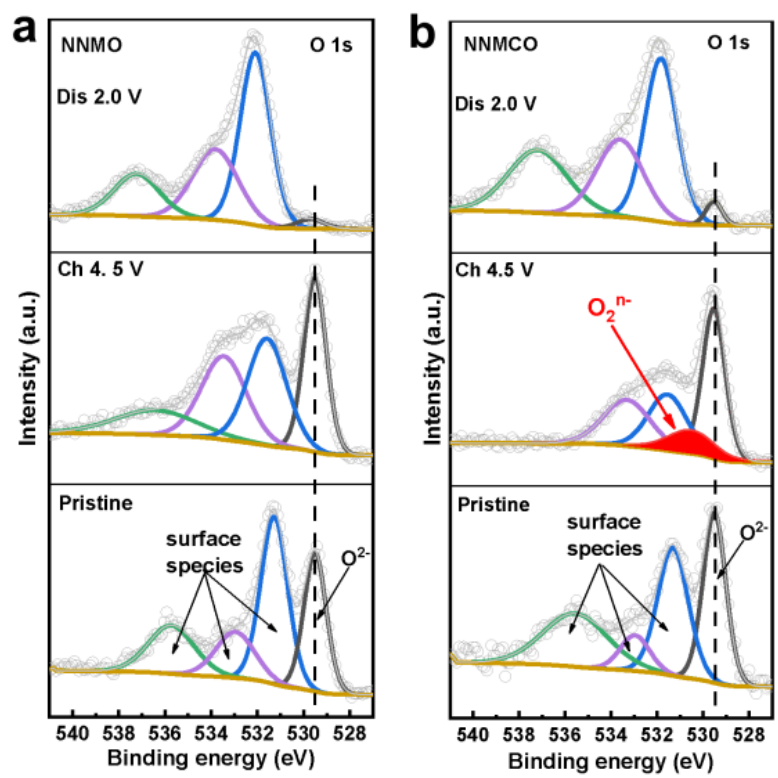

Figure S11. (a, b) O 1s XPS spectra collected from NNMO and NNMCO electrodes at different states of charge, respectively. It is worth noting that a significant decrease of the lattice oxygen signal is observed at fully discharged state. This phenomenon is related to the formation of carbonate-related species on the electrode surface, which has also been observed in previous reports. 5,6 
Table S1. Crystallographic parameters of $\mathrm{Na}_{0.6} \mathrm{Ni}_{0.2} \mathrm{Mn}_{0.7} \mathrm{Cu}_{0.1} \mathrm{O}_{2}$ refined by the Rietveld method.

\begin{tabular}{cccccc}
\hline Atom & P63/mmc site & $\mathrm{x}$ & $\mathrm{y}$ & $\mathrm{z}$ & Occupancy \\
\hline $\mathrm{Na}$ & $2 \mathrm{~d}$ & 0.66667 & 0.33333 & 0.25000 & 0.37 \\
$\mathrm{Na}$ & $2 \mathrm{~b}$ & 0 & 0 & 0.25000 & 0.23 \\
$\mathrm{Ni}$ & $2 \mathrm{a}$ & 0 & 0 & 0 & 0.2 \\
$\mathrm{Mn}$ & $2 \mathrm{a}$ & 0 & 0 & 0 & 0.7 \\
$\mathrm{Cu}$ & $2 \mathrm{a}$ & 0 & 0 & 0 & 0.1 \\
$\mathrm{O}$ & $4 \mathrm{f}$ & 0.66667 & 0.33333 & 0.07855 & 0.975 \\
& $\mathrm{a}=\mathrm{b}=2.95000 \AA, \mathrm{c}=11.46000 \AA, \alpha=\beta=90, \gamma=120, \mathrm{~V}=86.369280 \AA^{3}$ & \\
\hline
\end{tabular}

Table S2. Crystallographic parameters of $\mathrm{Na}_{0.6} \mathrm{Ni}_{0.2} \mathrm{Mn}_{0.7} \mathrm{O}_{2}$ refined by the Rietveld method.

\begin{tabular}{|c|c|c|c|c|c|}
\hline Atom & P63/mmc site & $\mathrm{x}$ & $\mathrm{y}$ & $\mathrm{z}$ & Occupancy \\
\hline $\mathrm{Na}_{\mathrm{e}}$ & $2 \mathrm{~d}$ & 0.66667 & 0.33333 & 0.25000 & 0.45 \\
\hline $\mathrm{Na}_{\mathrm{f}}$ & $2 b$ & 0 & 0 & 0.25000 & 0.15 \\
\hline $\mathrm{Ni}$ & $2 \mathrm{a}$ & 0 & 0 & 0 & 0.3 \\
\hline $\mathrm{Mn}$ & $2 a$ & 0 & 0 & 0 & 0.7 \\
\hline $\mathrm{O}$ & $4 \mathrm{f}$ & 0.66667 & 0.33333 & 0.07855 & 0.988 \\
\hline \multicolumn{6}{|c|}{$a=b=2.89905 \AA, c=11.26237 \AA, \alpha=\beta=90, \gamma=120, V=81.973190 \AA^{3}$} \\
\hline
\end{tabular}


Table S3. Structure parameters derived from Ni, Mn and Cu K-edge EXAFS spectra of NNMCO. (coordination numbers of $\mathrm{Ni}-\mathrm{O}, \mathrm{Mn}-\mathrm{O}$ and $\mathrm{Cu}-\mathrm{O}$ are all 6)

\begin{tabular}{|c|c|c|c|c|}
\hline & Path & $\mathrm{r} / \AA$ & $\sigma^{2}$ & $\mathrm{R}$ \\
\hline \multirow[t]{6}{*}{ NNMCO } & $\mathrm{Ni}-\mathrm{O}$ & $2.051 \pm 0.03$ & $0.009 \pm 0.005$ & 0.044 \\
\hline & $\mathrm{Ni}-\mathrm{TM}$ & $2.877 \pm 0.07$ & $0.006 \pm 0.002$ & \\
\hline & $\mathrm{Mn}-\mathrm{O}$ & $1.897 \pm 0.08$ & $0.0008 \pm 0.0007$ & 0.013 \\
\hline & Mn-TM & $2.894 \pm 0.08$ & $0.017 \pm 0.0006$ & \\
\hline & $\mathrm{Cu}-\mathrm{O}$ & $2.005 \pm 0.02$ & $0.013 \pm 0.002$ & 0.005 \\
\hline & $\mathrm{Cu}-\mathrm{TM}$ & $2.908 \pm 0.01$ & $0.013 \pm 0.002$ & \\
\hline \multirow[t]{4}{*}{ NNMO } & $\mathrm{Ni}-\mathrm{O}$ & $2.051 \pm 0.02$ & $0.006 \pm 0.002$ & 0.016 \\
\hline & Ni-TM & $2.891 \pm 0.02$ & $0.012 \pm 0.004$ & \\
\hline & $\mathrm{Mn}-\mathrm{O}$ & $1.897 \pm 0.008$ & $0.0013 \pm 0.008$ & 0.012 \\
\hline & Mn-TM & $2.889 \pm 0.007$ & $0.0013 \pm 0.0007$ & \\
\hline
\end{tabular}

r: bond length; $\sigma^{2}$ : Debye-Waller factor (disorder); R: R-factor

Table S4. The charge transfer and capacity contribution of each element of NNMCO at the first charging.

\begin{tabular}{|c|c|c|c|c|c|c|c|}
\hline & $\begin{array}{c}\mathrm{Ni} \\
\text { valence }\end{array}$ & $\begin{array}{c}\mathrm{Mn} \\
\text { valence }\end{array}$ & $\begin{array}{c}\mathrm{Cu} \\
\text { Valence }\end{array}$ & $\begin{array}{c}\mathrm{Ni} \\
\text { capacity } \\
\text { contribution }\end{array}$ & $\begin{array}{c}\text { Mn } \\
\text { capacity } \\
\text { contribution }\end{array}$ & $\begin{array}{c}\mathrm{Cu} \\
\text { capacity } \\
\text { Contribution }\end{array}$ & $\begin{array}{c}\mathrm{O} \\
\text { capacity } \\
\text { contribution }\end{array}$ \\
\hline Pristine & 2.07 & 3.86 & 2.06 & \multirow[b]{2}{*}{36.67} & \multirow[b]{2}{*}{26.20} & \multirow[b]{2}{*}{5.24} & \multirow[b]{2}{*}{65.09} \\
\hline $\begin{array}{c}\mathrm{Ch} \\
4.5 \mathrm{~V}\end{array}$ & 2.78 & 4.00 & 2.25 & & & & \\
\hline
\end{tabular}


Table S5. The charge transfer and capacity contribution of each element of NNMO at the first charging.

\begin{tabular}{|c|c|c|c|c|c|}
\hline & $\begin{array}{c}\mathrm{Ni} \\
\text { valence }\end{array}$ & $\begin{array}{c}\text { Mn } \\
\text { valence }\end{array}$ & $\begin{array}{c}\mathrm{Ni} \\
\text { capacity } \\
\text { contribution }\end{array}$ & $\begin{array}{c}\text { Mn } \\
\text { capacity } \\
\text { contribution }\end{array}$ & $\begin{array}{c}\mathrm{O} \\
\text { capacity } \\
\text { contribution }\end{array}$ \\
\hline Pristine & 2.21 & 3.80 & \multirow[b]{2}{*}{100.01} & \multirow[b]{2}{*}{23.69} & \multirow[b]{2}{*}{21.70} \\
\hline $\begin{array}{c}\mathrm{Ch} \\
4.5 \mathrm{~V}\end{array}$ & 3.46 & 4.00 & & & \\
\hline
\end{tabular}

\section{Reference}

1. Liu, Y.; Shen, Q.; Zhao, X.; Zhang, J.; Liu, X.; Wang, T.; Zhang, N.; Jiao, L.; Chen, J.; Fan, L. Z. Hierarchical Engineering of Porous P2- $\mathrm{Na}_{2 / 3} \mathrm{Ni}_{1 / 3} \mathrm{Mn}_{2 / 3} \mathrm{O}_{2}$ Nanofibers Assembled by Nanoparticles Enables Superior Sodium-Ion Storage Cathodes Adv. Funct. Mater. 2019, 30, 1907837.

2. Chen, T.; Liu, W.; Zhuo, Y.; Hu, H.; Zhu, M.; Cai, R.; Chen, X.; Yan, J.; Liu, K. Single-Phase P2-Type Layered Oxide with Cu-Substitution for Sodium Ion Batteries J. Energy Chem. 2020, 43, 148- 154.

3. Qiao, R.; Wang, Y.; Olalde-Velasco, P.; Li, H.; Hu, Y.-S.; Yang, W. Direct Evidence of Gradient $\mathrm{Mn}$ (II) Evolution at Charged States in $\mathrm{LiNi}_{0.5} \mathrm{Mn}_{1.5} \mathrm{O}_{4}$ Electrodes with Capacity Fading $J$. Power Sources 2015, 273, 1120- 1126.

4. Cheng, C.; Li, S.; Liu, T.; Xia, Y.; Chang, L. Y.; Yan, Y.; Ding, M.; Hu, Y.; Wu, J.; Guo, J.; Zhang, L. Elucidation of Anionic and Cationic Redox Reactions in a Prototype Sodium-Layered Oxide Cathode ACS Appl. Mater. Interfaces 2019, 11, 41304- 41312. 
5. Min Jia, H. L., Yu Qiao, Linlin Wang, Xin Cao, Jordi Cabana, and Haoshen Zhou. Elucidating Anionic Redox Chemistry in P3 Layered Cathode for Na Ion Batteries ACS Appl. Mater. Interfaces 2020, 12, 38249- 38255.

6. Zheng, W.; Liu, Q.; Wang, Z.; Wu, Z.; Gu, S.; Cao, L.; Zhang, K.; Fransaer, J.; Lu, Z. Oxygen Redox Activity with Small Voltage Hysteresis in $\mathrm{Na}_{0.67} \mathrm{Cu}_{0.28} \mathrm{Mn}_{0.72} \mathrm{O}_{2}$ for Sodium-Ion Batteries Energy Stor. Mater. 2020, 28, 300- 306. 